\title{
THE LECTURER-STUDENT CONVERSATIONAL STRUCTURE IN PRAGMATICS LEARNING INTERACTION
}

\author{
Diah Widya Ningrum, Didik Santoso \\ Magister Tadris Bahasa Inggris \\ Universitas Islam Negeri Sumatera Utara \\ E-Mail: diahwidyaningrum69@gmail.com
}

Received: 2021-07-22

Accepted: 2021-10-25

\begin{abstract}
This study aims to describe the structure of the lecturer-student conversation in the interaction of Pragmatics Class. This type of research is descriptive qualitative. The technique of data collection is done by recording and note-taking techniques. The data analysis technique is carried out by heuristic techniques. The results of the study show that the interactions of the lecturer and the students in Pragmatics Class have conversational structures: 1 ) turn taking of speech that occurs because of the opportunity to speak, 2) pauses (long and short) that occur due to the absence of feedback in the form of speech and speakers feel hesitant in conveying the message. 3) Overlaps that occur due to speech or the use of the same lingual element, 4) backchannels that occur because there is understanding and acceptance or approval of the speech, and 5) adjunct pairs that occur because of greetings, questions, and requests. This indicates that the process of the lecturer-students interaction runs well. The students feel enthusiastic for responding the lecturer's questions.
\end{abstract}

Keywords: conversational structure, turn taking, pauses, overlaps, backchannels, lecturer and student, and pragmatics learning interaction

\section{Introduction}

In every aspect of life, humans cannot be separated from conversation. Everyone freely interacts with others through conversation to meet the needs of his life. Conversation is a face-to-face speech between two or more people. It means that conversation is only limited to verbal interaction between the person speaking (the speaker) and the person being spoken to (the addressee) discussing a matter at a certain time.

However, it is often found that there is an interaction process between one or more people in media social in the form of writing. Basically, the interaction process can also be said as a conversation because it is actually an embodiment of oral conversation. Conversations in the form of writing can be found in drama texts, novels, short stories, and other conversations such as chatting on electronic social media. However, the speakers often have disruptions in the conversation, such as when backchannels, pauses, and overlaps happen. This becomes one of the studies of conversational analysis (CA).

Conversational Analysis (CA) is one of the methods to gather the data related to naturalistic conversational interaction. Heldner \& Edlund (2010) state that conversational analysis means a set of methods to learn a talk in interaction, such as backchannels, pauses, and overlaps in a conversation. 
The Lecturer-Student Conversational Structure in Pragmatics Learning Interaction, Diah Widya Ningrum, Didik Santoso

Previous studies have examined several parts of the conversation structure. Meydiana and Yanuarti (2019) did the research which focuses on analysis of pauses, overlaps and backchannels and Syarifuddin Yunus (2019) did the same research which focuses on one part of conversational structure, namely; turn taking.

Conversations also occur in learning interactions in the classroom. Lecturers and students interact with each others through conversation to achieve the learning objectives that have been set. The lecturer's conversation with the students describes a certain pattern of interaction in a lesson. However, the conversation between a lecturer and the students can also happen via on line, for example; zoom meeting. This happens because it is in pandemic COVID 19 era. Every student is forbidden to study in the classroom.

Moreover, these learning models provide more significant conversation opportunities because students are given the opportunity to interact freely both with lecturers and with fellow students in learning interactions. Thus, the researchers are interested in examining the structure of lecturer-students' conversations that occur in the interaction of Pragmatic Class.

Based on the description above, this study aims to describe the structure of lecturerstudents' conversations that occur in the interaction of PRAGMATICS class. The structure of conversation includes turn-taking, overlaps, pauses, back-channels, and adjacency pairs.

\section{Literature review}

Yule (2014) defines that pragmatics is the study of the connection between the users and the linguistics forms. Pragmatics itself permits people to analyze. In addition, Bilmes (2014) states pragmatics is always used to interpret the meaning in linguistics research. Of the two definitions stated by the authors, it can be concluded that pragmatics is a study of the use of language. How the language is used in a communication and understood by the listeners.

Conversation analysis (CA), according to Cutting (2005), is analysis of real - world situated contextualized talk. It means that conversation analysis is a study to analyze the interaction of human to other people such as initiating, responding, interrupting and offering.

A conversation contains structure. Conversational structure is also called conversational organization. In the structure of the conversation, there are five parts including Turn-taking, overlaps, pauses, back-channels, and adjacency pairs (Yule, 2006:121). The following explanation will discuss about the five parts of conversational structure.

1) Turn-taking is the process of changing roles between the speaker and the addressee in a conversation that does not contain signs or rules. This means that every actor in the conversation has the same right to speak. When the speaker speaks and cannot adjust the control, the speaker has the right to take a turn to speak.

2) Pause is a silence in a conversation that allows marking a shift in speech. Pauses in conversation have three forms, namely short, medium, and long pauses. Short pause is a short silence as a form of doubt and a long pause is a long silence. Pauses in conversation have several uses, namely pauses used before switching ideas, emphasizing, according to the demands of the situation and inviting responses.

3) Overlap is the state of the speaker and the addressee speaking at the same time. Overlap implies that in a conversation it is called overlaps if there is an overlap speech between the speaker and the addressee at the same time naturally or not artificially. 
4) Back-channel is the response expected by the speaker to the addressee (can be in the form of body movements or gestures). The response can be in the form of words such as "ah-ha", "uh-huh", "yeah", nodding, smiling, facial expressions and also gestures. With the back-channel, speakers feel that the speaker understands the conversation well enough.

5) Adjacency pairs or side-by-side pairs are patterns that occur automatically in conversation and always consist of two parts spoken by different parties. Hutchby \& Wooffitt (2008) state that adjacency pairs are a series of two paired utterances, produced by different speakers, there are first and second parts, as well as having has a type so that the first part always requires the second part. In adjunctive pairs, the first utterance always quickly creates the second utterance because it is an automatic pairing; for example, greetings have a partner to answer greetings and utterances in the form of questions that always have a partner, namely an answer.

\section{Research Method}

In this study, the researchers use conversations which contain backchannel, pauses, overlaps, adjunct, and turn taking. That is why the method of this study is qualitative research. This method is used to explain the nature phenomenon that occurred.

The data in this study are verbal data in the form of lecturer and students' speech which shows the existence of turn taking, overlaps, pauses, back-channels, and adjacency pairs. The data was obtained when the lecturer and students had conversations in PRAGMATICS class for two meetings. Sources of data in this study are lecturer and students of S2 English Department. The selection of the data source is based on the fact that the researcher includes in it. So, this makes the researcher easy to collect the data.

The technique used to collect data in this research is recording technique and notetaking technique. The recording technique is used to record the lecturer's conversation with the students during the learning interaction. The note-taking technique is used when the recording device has been turned off, but there are still conversations between the lecturer and students that contain data. The technique used to analyze the data is heuristic technique. Heuristic technique is a technique used by the researcher to interpret certain lingual elements or speech. At first, the speech from the lecturer to the students became a problem, a provisional hypothesis is determined, tested based on the context in the field, and then conclusions are described.

\section{Results and Discussion}

\subsection{Results}

\section{a. Turn - taking}

The turn taking of speech is the process of changing roles between the speaker and the addressee in a conversation that does not contain signs or rules. This means that every actor in the conversation has the same right to speak. Take turns in the conversation between the lecturer and the students in the interaction of English learning are shown in the following data.

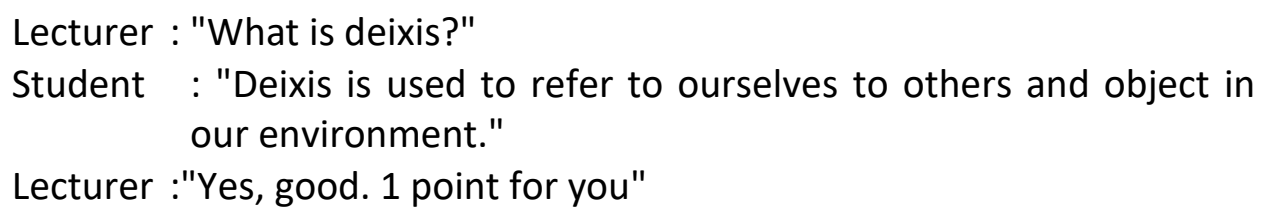


The Lecturer-Student Conversational Structure in Pragmatics Learning Interaction, Diah Widya Ningrum, Didik Santoso

The context of the conversation above occurs during the learning activities. The lecturer asks the students the definition of deixis. In this case, the lecturer provides opportunities for students to answer questions. The opportunity given by the lecturer appears in the silence of the lecturer after asking questions to students. At that time, students immediately took the opportunity given by the lecturer to answer the question. From the data above, it appears that there is a turn-taking in speech pattern from the lecturer-student-lecturer. Thus the structure of this conversation is included in the turn-taking of speech.

\section{b. Pause}

A pause is a silence in a conversation that allows marking a shift in speech. Pauses in conversation have three forms, namely short, medium and long pauses. Short pause is a short silence as a form of doubt and a long pause is a long silence. The pauses in lecturerstudent conversations in Indonesian language learning interactions are shown in the following data.

\section{Short Pause}

Lecturer: "There are 6 kinds of Deixis, mention them!"

Student : "The six kinds of Deixis are Person, Spatial-Temporal. Third, Discourse and Temporal-and the last is Social."

The context of the conversation above occurs in the learning activities. At that time, group 6 had just finished presenting and asking and answering questions with students between groups. Then, the lecturer asked questions to the group that had just presented the results of their discussion. One of the students immediately answered the lecturer's question but had doubts in the middle of the speech. The doubts are marked with a dash. There was a pause after saying the word spatial and the word temporal. This indicates a short pause ( 2 seconds) in the conversation.

\section{Long Pause}

$\begin{array}{ll}\text { Lecturer } & \text { : “Any question?" (15 seconds) } \\ \text { Lecturer } & \text { : "If anyone wants to ask, please!" (10 seconds) } \\ \text { Lecturer } & \text { : "Nothing. I will review material that has been presented by } \\ & \text { your friend. Mention } 3 \text { experts of cross cultural pragmatics!" } \\ \text { Student } & \text { : "Me." (A student raises hand) }\end{array}$

The context of the conversation above occurred at the time of the closing of the learning activity. At that time the lecturer gave the students the opportunity to ask questions about the material that had not been understood, but the students did not take advantage of the opportunity. Because students did not take advantage of the opportunity, there was a long pause in the lecturer's speech after the words ask and please. This indicates a long pause (10-15 seconds) in the conversation. 


\section{c. Overlap}

Overlap is the state of the speaker and the addressee speaking at the same time. The overlap in lecturer-student conversations in PRAGMATICS learning interactions is shown in the following data.
Lecturer
: "Well, there are three of mindset of cross cultural pragmatics. They are firstly was ethnocentric orientation, the second was -polycentric orientation-,
Some Students : --polycentric orientation-
Lecturer
: "And the third is -geocentric orientation-."
Some Students
: "-geocentric orientation -"

The context of the conversation above occurs at the end of the learning activity. At that time the lecturer was reviewing the material from beginning to end. When the lecturer is talking, the students also talk namely the polycentric orientation phrases and geocentric orientation at the same time. Thus, the structure of this conversation includes overlaps.

\section{d. Backchannel}

Back-channel is the response that the speaker expects to the addressee (can be in the form of body movements or gestures). The back-channel in lecturer-student conversations in PRAGMATICS learning interactions can be seen in the following data.

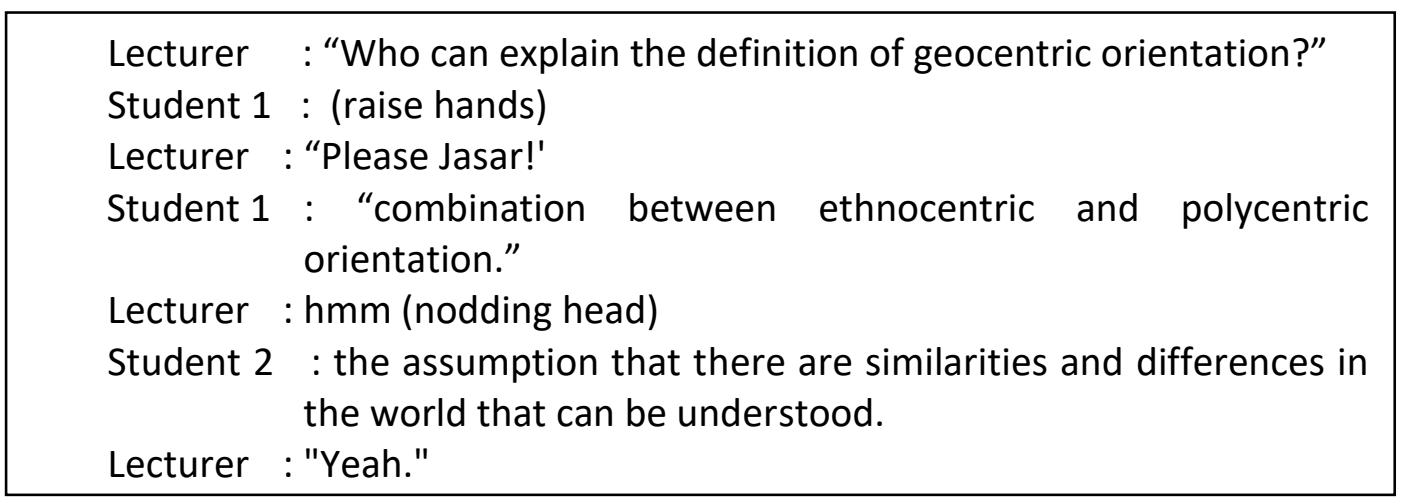

The context of the conversation above occurs in the opening of the learning activity, namely apperception. At that time the lecturer asked the material last week. After the lecturer asks, students immediately respond to answer the lecturer's questions. On the sidelines of the answers given by the students, the lecturer responded "hmm" and "yes" which is a sign that the student's speech is accepted. Thus, the structure of this conversation includes a back-channel.

\section{e. Adjacency Pairs}

Adjacency pairs or side-by-side pairs are patterns that occur automatically in conversation and always consist of two parts spoken by different parties. Attachment pairs in lecturer-student conversations in Indonesian language learning interactions are shown in the following data.

Student : "How are you, mam"

Lecturer: "I'm fine, How is about you?" 
The Lecturer-Student Conversational Structure in Pragmatics Learning Interaction, Diah Widya Ningrum, Didik Santoso

The context of the conversation above occurs in the opening of learning activities. At that time, the lecturer has just joined the zoom meeting class, and then the students welcomed the lecturer's arrival by greeting the lecturer. After students gave greetings, of course the lecturer immediately responds to the greetings given by students. Giving greetings and responding to greetings is an automatic pairing in conversation. Thus, the structure of this conversation includes an adjacency pair.

\subsection{Discussion}

Based on data analysis, it was found that there was a structure of lecturer-student conversation in the interaction of PRAGMATICS class. Conversational structures found include turn-taking, pauses, overlaps, back-channels, and adjacency pairs.

In this study, the findings of turn - taking are based on the theory of conversational structure proposed by Yule. Yule (2006: 122) suggests that the turn taking of speech is a process of changing roles between the speaker and the addressee in a conversation where there are no signs or rules. This means that every actor in the conversation has the same right to speak. When the speaker speaks and cannot adjust the control, the speaker has the right to take a turn to speak.

Based on this theory, the findings in this study meet the occurrence of shifts in speech or the change of speaking roles between lecturer and students in Pragmatics Class. Turntaking in lecturer-student conversations occur because of opportunities to speak in learning interactions. The turn-taking system that occurs has been recognized and realized by both lecturer and students. Therefore, they are aware of getting that turn, guarding, and giving or releasing a turn to the other person.

Like the turn-taking of speech, pause is also based on the theory of conversation structure proposed by Yule. Yule (2006: 125) suggests that the silence in a conversation that allows it to indicate a shift in speech. Pauses in conversation have three forms, namely short, medium and long pauses. Short pause is a short silence as a form of doubt and a long pause is a long silence.

Based on this theory, the findings in this study prove that in the conversation between lecturer and students in pragmatics class, there is a pause. The pause in the lecturer-student conversation that occurs in the interaction of learning pragmatics, there are long pauses and short pauses. Long pauses and short pauses occur in the middle of speech and at the end of speech. The pause at the end of the speech causes a long pause, while the pause in the middle of the speech causes a short pause. The long pause at the end of the speech in learning Pragmatics is caused by the non-response in the form of speech from the speaker to what the speaker is talking about. The short pause in the middle of speech in learning Pragmatics is caused by the speaker's hesitation in conveying the message. The doubt is an implication of the process of thinking about something so that it can be conveyed to the speaker.

Overlap is based on Yule's theory. Yule (2006: 124) explains, an overlap is the state of speakers and addressees who speak at the same time. Based on this theory, the findings in this study prove that there are overlaps in the conversations between lecturers and students in learning pragmatics. Overlaps in lecturer-student conversations occur because of the speech or use of the same lingual element. That is, when the lecturer and students talk at the same time, the object what is being discussed is the same object and in the exact same language. 
Back-channel is also based on the theory of Yule (2006: 129) which states that the response expected by the speaker to the addressee (can be in the form of body movements or gestures). The response can be in the form of words such as "ah-ha", "uh-huh", "yeah", nodding, smiling, facial expressions and also gestures. With the backchannel, speakers feel that the speaker understands the conversation well enough. Based on this theory, the findings in this study prove that there is a backchannel in the conversation between lecturer and students in pragmatics class. Backchannels that occur in learning interactions are caused by the speaker understanding and accepting or agreeing with what the speaker is saying.

The last part of the conversation structure is the adjacency pair. Adjacency pairs are based on Yule's theory. Yule (2006: 132) explains that adjacency pairs or side-by-side pairs are patterns that occur automatically in conversation and always consist of two parts spoken by different parties. Based on this theory, the findings in this study prove that in the conversation between lecturer and students in pragmatics class, there are adjacency pairs. The adjacency pairs found were caused by greetings so that there was an immediate response to receive greetings, there were questions that were responded by giving answers, and there were requests that were responded with acceptance.

\section{Conclusion}

This study proves that the conversation between lecturer and students in the interaction of Pragmatics class shows the presence of turn taking, overlapping, pauses, backchannels, and adjacency pairs. Take turns in lecturer-student conversations occur because of opportunities to speak in learning interactions. The turn-taking system that has occurred has been recognized and realized by both lecturer and students.

Pauses are also found in lecturer and student conversations. The pauses that appear are long pauses and short pauses that occur in the middle of the speech and at the end of the speech. A long pause occurs at the end of the speech and is caused by the absence of a response back in the form of speech from the speaker to what the speaker is talking about. A short pause occurs in the middle of speech and is caused by the speaker's hesitation in conveying the message. Overlaps in lecturer-student conversations occur because of the speech or use of the same lingual element. Backchannels that occur in learning interactions are caused by the speaker understanding and accepting or agreeing with what the speaker is saying. The pairs of adjacency found were caused by greetings so that there was an immediate response to receive greetings, there were questions that were responded by providing answers.

\section{References}

Bilmes, J. (2014). Preference and the Conversation Analytic Endeavor, Journal of Pragmatics, 64, 52-71.

Heldner, M., \& Edlund, J. (2010). Pauses, gaps and overlaps in conversations. Journal of Phonetics, 38 (4), 555-568.

Cutting, J. (2005). Pragmatics and discourse: A resource book for student. London: Routledge.

Hutchby, I., \& Wooffitt, R. (2008). Conversation Analysis: Principles, Practices and Applications. Cambridge: Blackwell Publishers Ltd.

Meydiana, Kuswandi, and Yanuarti, Apsari (2019). An Analysis of Pauses, Overlaps and Backcahnnels in Conversation in Vlog by Nessie Judge. PROJECT Professional Journal of English Education. Vol. 2 No 3 p-ISSN 26146320 
The Lecturer-Student Conversational Structure in Pragmatics Learning Interaction, Diah Widya Ningrum, Didik Santoso

Syarifuddin Yunus (2020). The Turn Taking Strategy Used by Prabowo and Jokowi in the Presidential Election Debate 2019. Science and Technology Publications, Lda. DOI: 10.5220/0009001504600467.

Yule, G. (2006). Pragmatics. Oxford: Oxford University Press.

Yule, G. (2014). The Study of Language. Cambridge: Cambridge University Press. 